\title{
Evidence Report: Genetic and metabolic testing on children with global developmental delay
}

Report of the Quality Standards Subcommittee of the American Academy of Neurology and the Practice Committee of the Child Neurology Society

미

D.J. Michelson, MD

M.I. Shevell, MD

E.H. Sherr, MD

J.B. Moeschler, MD

A.L. Gropman, MD

S. Ashwal, MD

Address correspondence and reprint requests to American Academy of Neurology, 1080 Montreal Avenue, St. Paul, MN 55116

guidelines@aan.com

\section{ABSTRACT}

Objective: To systematically review the evidence concerning the diagnostic yield of genetic and metabolic evaluation of children with global developmental delay or intellectual disability (GDD/ID).

Methods: Relevant literature was reviewed, abstracted, and classified according to the 4-tiered American Academy of Neurology classification of evidence scheme.

Results and Conclusions: In patients with GDD/ID, microarray testing is diagnostic on average in $7.8 \%$ (Class III), G-banded karyotyping is abnormal in at least $4 \%$ (Class II and III), and subtelomeric fluorescence in situ hybridization is positive in 3.5\% (Class I, II, and III). Testing for X-linked ID genes has a yield of up to $42 \%$ in males with an appropriate family history (Class III). FMR1 testing shows full expansion in at least $2 \%$ of patients with mild to moderate GDD/ID (Class II and III), and MeCP2 testing is diagnostic in $1.5 \%$ of females with moderate to severe GDD/ID (Class III). Tests for metabolic disorders have a yield of up to $5 \%$, and tests for congenital disorders of glycosylation and cerebral creatine disorders have yields of up to $2.8 \%$ (Class III). Several genetic and metabolic screening tests have been shown to have a better than $1 \%$ diagnostic yield in selected populations of children with GDD/ID. These values should be among the many factors considered in planning the laboratory evaluation of such children. Neurology ${ }^{\circledR} 2011 ; 77: 1629-1635$

\section{GLOSSARY}

AAN = American Academy of Neurology; BAC = bacterial artificial chromosome; $\mathbf{C D G}=$ congenital disorders of glycosylation; $\mathbf{D Q}=$ developmental quotient; $\mathbf{D X L}=$ definite $X$-linkage; $\mathbf{G D D}=$ global developmental delay; ID = intellectual disability; IEM = inborn errors of metabolism; PXL = possible X-linkage; UXL = unknown X-linkage; $\mathbf{X L I D}=$ X-linked intellectual disability .

Children aged less than 6 years are considered to have global developmental delay (GDD) if they perform more than 2 SDs below age-matched peers in 2 or more aspects of development. ${ }^{1,2}$ GDD affects an estimated $1 \%-3 \%$ of children, many of whom will demonstrate intellectual disability (ID). ${ }^{1,2}$ In this evidence report, a developmental quotient Editorial, page 1586 (DQ) or IQ of $50-70$ is considered mild impairment, and a DQ or IQ of less than 50 is considered moderate to severe impairment.

The previous American Academy of Neurology and Child Neurology Society guideline regarding evaluation of GDD concluded that several diagnostic tests had a greater than $1 \%$ yield, including G-banded karyotyping, FMR1 gene testing, subtelomeric fluorescence in situ hybridization (StFISH) testing, $\mathrm{MeCP} 2$ gene testing in girls with moderate to severe impairment, neuroimaging (MRI preferred to CT), and assessments for visual and hearing deficits. ${ }^{3}$ Genetic advances prompted the development of this updated report focused solely on the diagnostic yield of genetic and metabolic testing.

DESCRIPTION OF THE ANALYTIC PROCESS Literature searches for this evidence report were com-

From the Departments of Pediatrics and Neurology (D.J.M., S.A.), Loma Linda University School of Medicine, Loma Linda, CA; Departments of Neurology, Neurosurgery, and Pediatrics (M.I.S.), McGill University, Montreal, Canada; Departments of Neurology and Pediatrics (E.H.S.), University of California, San Francisco; Division of Medical Genetics (J.B.M.), Department of Pediatrics, Dartmouth-Hitchcock Medical Center, Lebanon, NH; and Departments of Pediatrics and Neurology (A.L.G.), George Washington University School of Medicine and the Health Sciences, Children's National Medical Center, Washington, DC.

Appendices e-1-e-11 and references e1-e167 are available on the Neurology ${ }^{\circledR}$ Web site at www.neurology.org.

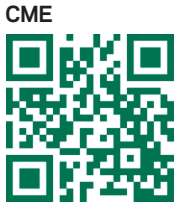

Approved by the Quality Standards Subcommittee on July 10, 2010; by the AAN Practice Committee on August 19, 2010; by the Child Neurology Society (CNS) Practice Committee on August 19, 2010; by the AAN Board of Directors on July 18, 2011; and by the CNS Board of Directors on August 20, 2011.

Study funding: This evidence report was funded by the American Academy of Neurology and the Child Neurology Society. No author received honoraria or financial support to develop this document.

Disclosure: Author disclosures are provided at the end of the article. 
pleted for the years 1980-2009 and resulted in 7,000 abstracts, 367 of which were selected for full-text review. See appendix e-2, a and b, on the Neurology ${ }^{\circledR}$ Web site at www.neurology.org for information on databases searched, search terms used, and article classification. Table e-1 presents the diagnostic yield in different populations for various testing methods.

ANALYSIS OF EVIDENCE Genome-wide genetic testing. Genetic evaluation of a child with GDD/ID who lacks distinctive syndromic features generally begins with genome-wide testing for DNA rearrangements. G-banded karyotyping detects chromosomal structural changes with a resolution of 3-5 million base pairs (3-5 Mb). StFISH and microarray tests detect specific copy number changes (most commonly deletions or duplications) for which the specific probes are constructed. ${ }^{4}$ Microarray tests based on bacterial artificial chromosome (BAC) probes typically have a resolution of $1 \mathrm{Mb}$, and those based on oligonucleotide probes typically have resolutions of 30,000-35,000 base pairs (kb). Microarray testing detects well-known syndromes (e.g., Velo-cardio-facial syndrome or Williams syndrome) as well as previously undescribed genomic disorders. Interpretation of microarray abnormalities of uncertain significance will often require referral for a medical genetics consultation. Abnormal results are considered diagnostic when previously reported to be causative and are considered possibly diagnostic when absent in unaffected parents. 5 When abnormal results of uncertain significance are inherited from an unaffected parent, interpretation should be made cautiously, given the possibility of variable penetrance.

Microarray studies. The results of studies reporting microarray test yields are summarized in appendix e-3. Twenty-seven Class III studies of 6,559 subjects with GDD/ID found microarray testing to be diagnostic in $7.8 \%$ (range $0 \%-50 \%$ ). ${ }^{6-32}$ A higher yield of $10.2 \%$ $(0 \%-50 \%)$ was found in the 18 studies in which the 1,524 subjects were described as syndromic (facial dysmorphism, congenital anomalies, or neurologic symptoms). ${ }^{6-23}$ A lower yield of $6.4 \%$ was found in the one study in which all 94 subjects were described as nonsyndromic. $^{24}$

G-banded karyotype studies. The results of studies reporting karyotype test yields are summarized in appendix e-4. A Class II study of 342 patients with unexplained GDD/ID found that $4 \%$ had an abnormal karyotype. ${ }^{33}$ Nine Class III studies found a similar yield of $4.2 \%(2.9 \%-11.7 \%)$ in $4,032 \mathrm{pa}$ tients. $^{34-40, \mathrm{e} 1, \mathrm{e} 2}$ Three Class III studies of 70 subjects with syndromic GDD/ID found a much higher yield of $18.6 \%(6.7 \%-50 \%) .{ }^{36,38, \mathrm{e} 3}$

StFISH studies. The results of studies reporting StFISH test yields are summarized in appendix e-5.
One Class I study found StFISH abnormalities in $5.9 \%$ of 466 patients with unexplained GDD/ID. ${ }^{\text {e4 }}$ Two Class II studies of 374 patients found StFISH abnormalities in 4.8\% (4.2\%-5.1\%). ${ }^{\mathrm{e}, \mathrm{e} 6}$ Thirtyseven Class III StFISH studies found abnormalities in $3.5 \%(0 \%-20 \%)$ of 18,583 patients with either

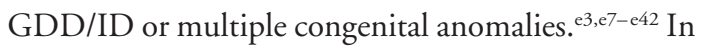
subjects with milder impairment, StFISH had a yield of $0.5 \%$ in 1 Class I study of 182 patients and of $1.7 \%(0 \%-10.3 \%)$ in 6 Class III studies of 290 patients. In subjects with moderate/severe impairments, StFISH had a yield of $7.4 \%$ in 1 Class I study of 284 patients and of $8.5 \%(0 \%-12.5 \%)$ in 7 Class III studies of 460 patients. In subjects with syndromic features, StFISH had a yield of $4.2 \%$ in 1 Class II study of 120 patients and of $5.4 \%$ $(1.3 \%-20 \%)$ in 11 Class III studies of 1,439 patients. Two studies demonstrated that the use of clinical checklists to restrict StFISH testing to patients with more severe GDD/ID, syndromic features, and a positive family history increased the yield to $28.6 \%$ e $^{\text {e7 }}$

Few studies have directly compared genome-wide genetic tests. One Class III study $(\mathrm{n}=94)$ comparing microarray with StFISH found abnormalities in 9 subjects, including 6 that were seen only by microarray. ${ }^{\text {e4 }}$ The same study reported that $12 \%$ of 424 subjects with syndromic GDD/ID had microarray abnormalities, most of which were interstitial (i.e., not in areas screened by StFISH). Another Class III study of BAC-based microarray in 278 patients with GDD/ID found subtelomeric abnormalities in 3 patients who had prior normal StFISH test results. ${ }^{30}$ Most studies of microarrays and StFISH tests were done on children whose karyotype testing had been normal. It is reasonable to hypothesize that the yields would have been higher if subjects were not initially screened by karyotyping.

Conclusions. Microarray testing is abnormal on average in $7.8 \%$ of subjects with GDD/ID and in $10.6 \%$ of those with syndromic features (Class III). Karyotype studies are abnormal in at least $4 \%$ of subjects with GDD/ID and in 18.6\% of those with syndromic features (Class II and III). StFISH testing is abnormal in at least $3.5 \%$ of subjects with GDD/ID, in at least $4.2 \%$ of those with syndromic features, in as few as $0.5 \%$ of those with mild impairment, and in at least $7.4 \%$ of those with moderate/severe impairment (Class I, II, and III).

X-linked genetic testing. X-linked intellectual disability (XLID) is estimated to account for approximately $10 \%$ of all cases of ID. ${ }^{\text {e } 45}$ More than 70 genes responsible for XLID in which mutations have been identified have been cloned. ${ }^{446}$ There are more than 100 
genes that have been identified by linkage and not yet cloned and another 9 segmental duplications of the X chromosome.

$X$-linked ID gene studies. The results of studies reporting XLID gene test yields are summarized in appendix e-6. One Class III study compiled sequencing efforts from 600 families with multiple males affected by either GDD/ID or other neurologic abnormalities that remained unexplained after karyotype and FMR1 testing. ${ }^{\text {e47 }} \mathrm{X}$-linkage was considered definite (DXL) in 325 families, possible (PXL) in 191 families, and unknown (UXL) in 84 families. Sixteen genes were sequenced in more than 100 families, and mutations were found in $42 \%$ of families with DXL and $17 \%$ of families with PXL. Mutations in XLID genes also were found in some males from UXL families.

The XLID genes tested individually in these families include the $A R X, J A R 1 D 1 C$, and SLC6A8 genes. One Class III study from the European XLMR cohort identified $A R X$ mutations in $7.5 \%$ of $147 \mathrm{DXL}$ families and $1.5 \%$ of 136 PXL families. ${ }^{\text {e48 }}$ Another Class III study found $A R X$ mutations in $5 \%$ of 80 DXL families and $1.2 \%$ of 85 PXL families. ${ }^{449}$ Two Class III studies found JARIDIC mutations in 3.1\% of 323 DXL or PXL families. ${ }^{\mathrm{e} 0, \mathrm{e} 51}$ One Class III study found JAR1D1C mutations in $8.6 \%$ of 23 DXL or PXL families, $0.6 \%$ of 172 UXL families, and $1.1 \%$ of 92 isolated males with short stature. e $^{-5}$ One Class III study found SLC6A8 mutations in $2.1 \%$ of 288 patients from DXL or PXL families, ${ }^{\text {e5 }}$ whereas another Class III study found SLC6A8 mutations in $0.4 \%$ of 478 unrelated males with unexplained GDD/ID. . $^{54}$

FMR1 gene studies. The FMR1 gene at Xq27.3 normally contains 5-40 consecutive CGG trinucleotide repeats. When 55-200 repeats are present, the gene has an unstable "premutation" length that is prone to further expansion during meiosis. A full expansion to more than 200 repeats is associated with the dysmorphism, ID, and social impairment of fragile X syndrome.

The results of studies reporting FMR1 gene test yields are summarized in appendix e-7. Four Class II studies found full FMR1 expansions in 2\% (0.7\%$6.4 \%)$ of 2,226 patients $(55.5 \%$ males $)$ with unexplained mild/moderate GDD/ID. ${ }^{\text {e55-e58 }}$ Another 17 Class III studies $(\mathrm{n}=24,216)$ found full expansions in $2.5 \%(0 \%-11.7 \%) .^{35,39, \mathrm{e} 59-\mathrm{e} 73}$ Full FMR1 expansions were found in $2.6 \%(1 \%-8 \%)$ of 1,236 male subjects from 4 Class II studies ${ }^{\mathrm{e5}-\mathrm{e} 58}$ and in $2.9 \%$ $(2 \%-13.7 \%)$ of 15,698 male subjects from 6 Class

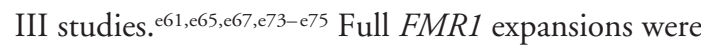
found in $1.3 \%(0 \%-7 \%)$ of 1,340 female subjects from 6 Class II studies ${ }^{\mathrm{e} 55-\mathrm{e} 58, \mathrm{e} 76, \mathrm{e} 77}$ and 1.1\% (0.7\%-
7.5\%) of 6,315 female subjects from 3 Class III studies. ${ }^{\text {e61,e65,e73 }}$ Two Class III studies found full FMR1 expansion in only $1(0.3 \%)$ of 291 subjects with severe GDD/ID. ${ }^{\mathrm{e} 78, \mathrm{e} 79}$ In 3 Class III studies, full FMR1 expansion was seen in 15.2\% (9.7\%$55 \%$ ) of 164 boys with high clinical scores for fragile X syndrome but in none of 411 boys with low scores. e $^{\mathrm{8} 0-\mathrm{e} 82}$

MeCP2 gene studies. Mutations in the $\mathrm{MeCP} 2$ gene are associated with Rett syndrome, an X-linked dominant neurodevelopmental disorder primarily affecting girls. The results of studies reporting $\mathrm{MeCP} 2$ gene test yields are summarized in appendix e-8. Five Class III studies found MeCP2 mutations in $0.4 \%$ $(0 \%-1.5 \%)$ of 1,194 subjects (70\% male) with moderate/severe GDD/ID. ${ }^{\text {e84-e88 }}$ Four Class III studies found MeCP2 mutations in $1.5 \%(0 \%-4.4 \%)$ of 324 girls with moderate/severe GDD/ID. e84,e86,e88,e89 Nine Class III studies found $\mathrm{MeCP} 2$ mutations in $0.2 \%-$ $0.4 \%$ (4 mutations of unclear significance) of 2,291 boys with GDD/ID. e84,e86,e88,e90-e95

Conclusions. Mutations in X-linked genes may explain up to $10 \%$ of all cases of GDD/ID. Testing of XLID genes has a yield of $42 \%$ in males from definitely X-linked families and of $17 \%$ in males from possibly X-linked families (Class III). FMR1 testing has a combined yield of at least $2 \%$ in male and female subjects with mild GDD/ID (Class II and III). MeCP2 mutations are found in $1.5 \%$ of girls with moderate/severe GDD/ID and in less than $0.5 \%$ of males with GDD/ID (Class III).

Metabolic testing. Inborn errors of metabolism (IEMs) are a diverse collection of disorders of intermediate (carbohydrate, amino acid, and lipid) metabolism that are caused by dysfunction of an enzyme encoded by a single gene. IEMs have wide phenotypic variation and can present with static encephalopathy but may be suspected on the basis of historical features (affected family members, parental consanguinity, episodic decompensation, developmental regression), physical findings (coarse facial features, organomegaly), or neuroimaging findings (abnormal myelination, striatal necrosis).

The results of studies reporting metabolic test yields are summarized in appendix e-9. One Class II study of 151 patients with GDD/ID found metabolic screening tests to have a 5\% yield. ${ }^{\text {e9 }}$ Seven Class III studies found a yield of 1.8\% (0\%-4.6\%) in 3,862 patients with GDD/ID. ${ }^{40, e 39, e 97-e 102}$ In one of these studies, selective IEM testing performed because of clinical suspicion was diagnostic in $8-10$ (range $3.7 \%-4.6 \%$ ) of 216 patients with unexplained GDD/ID. ${ }^{\mathrm{e} 9}$ None of the 176 screening tests for plasma amino acids and urine organic acids was abnormal. Four children (1.4\%) with congenital dis- 
orders of glycosylation (CDG) were identified by plasma sialotransferrin analysis, 2 children had abnormal serum cholesterol and 7-dehydrocholesterol levels suggestive of Smith-Lemli-Opitz syndrome, 2 had laboratory evidence of a mitochondrial disorder, 1 had laboratory evidence of a peroxisomal disorder, and 1 had abnormal CSF biogenic amine levels. In another of these Class III studies, metabolic testing was redone in 433 children whose GDD/ID remained unexplained after genetic/metabolic testing that included a standard karyotype; urine for amino acids, organic acids, mucopolysaccharides, oligosaccharides, uric acid, sialic acid, purines, and pyrimidines; and plasma for amino acids, acylcarnitines, and sialotransferrins. ${ }^{\text {e102 }}$ Screening tests were repeated, and additional testing, including CSF studies, was guided by clinical suspicion. IEMs were identified and confirmed in 12 patients (2.7\%), including 3 with mitochondrial disorders, 2 with creatine transporter disorders, 2 with short-chain acylCoA dehydrogenase deficiency, and 1 each with Sanfilippo IIIa, a peroxisomal disorder, a CDG, 5-methyltetrahydrofolate reductase deficiency, and GLUT1 deficiency.

Several studies have screened for disorders of creatine synthesis and transport by measuring urine creatine and guanidinoacetate. One Class III study screened 188 male and female subjects with unexplained GDD/ID and identified 5 (2.7\%) boys with severe to profound impairment who had abnormalities. ${ }^{\text {e103 }}$ Another Class HI study of 1,600 unrelated male and female children with GDD/ID and/or autism found that 34 (2.1\%) had abnormal urine creatine-to-creatinine ratios, although only $10(0.6 \%)$ had abnormal repeat tests and only 3 $(0.2 \%)$ were found to have a mutation in the X-linked SLC6A8 gene. ${ }^{\text {el04 }}$ As mentioned earlier, a Class III study found SLC6A8 mutations in $0.4 \%$ of 478 unrelated males with unexplained GDD/ ID. ${ }^{\text {e105 }}$ Another Class III study of 180 institutionalized subjects with unexplained severe to profound GDD/ID found $5(2.8 \%)$ with mutations in the autosomal GAMT gene, $2(1.1 \%)$ of which were clearly pathologic. ${ }^{\mathrm{e} 106}$

Conclusions. Screening for IEMs in children with GDD/ID has a yield of between $0.2 \%$ and $4.6 \%$, depending on the presence of clinical indicators and the range of testing performed (Class III). Testing for CDGs has a yield of up to $1.4 \%$, and testing for creatine synthesis and transport disorders has a yield of up to $2.8 \%$ (Class III).

CLINICAL CONTEXT We reviewed numerous studies that found yields of more than $1 \%$ for various genetic and metabolic tests in children with unex- plained GDD/ID. Most of the studies were classified as providing Class III evidence because their subjects were drawn from referral-based neurology and genetics specialty clinics, where most decisions regarding testing are and will continue to be made. The yield of a given test is admittedly only one of many factors to be considered when planning a diagnostic testing strategy for a child with GDD or ID. Other factors include the ability of a test to identify a treatable disorder; the pretest probability of presence of a disease based on clinical features and family history; and the availability, invasiveness, and cost of testing.

An etiologic diagnosis for GDD or ID only occasionally leads to a specific therapy that improves the child's outcome; however, it often leads to other benefits for the child and the child's family. These benefits include relieving caregivers of anxiety and uncertainty, empowering caregivers to become involved in support and research networks, limiting further diagnostic testing that may be costly or invasive, improving understanding of treatment and prognosis, anticipating and managing associated medical and behavioral comorbidities, allowing for counseling regarding recurrence risk, and preventing recurrence through screening for carriers and prenatal testing. ${ }^{\text {107 }}$

The evaluation of children with neurodevelopmental disabilities is evolving as previously unrecognized disease mechanisms are uncovered and novel and increasingly sensitive methods for diagnosis are introduced, improving etiologic yields. ${ }^{\text {e108 }}$ Physicians who develop their familiarity with the clinical features and testing of genetic and metabolic disorders will likely be more efficient in their patient evaluations, ordering fewer tests rather than more. Many children seen for GDD/ID do not present with syndromic features or a positive family history.

Microarray is the genetic test with the highest diagnostic yield in children with unexplained GDD/ID. The resolution of the current generation of commercially available, genome-wide, oligonucleotide-based microarray testing is 700 base pairs, 30 to 40 times higher than the oligo-based tests previously used in studies of GDD/ID and 1,000 times higher than older BAC-based microarrays. Laboratories now offer single nucleotide polymorphism sensitive microarray that detects and describes consanguinity or uniparental disomy. Studies on the yield of these more advanced microarray tests are anticipated in the near future. Currently, microarray testing can identify only unbalanced copy number changes and is insufficiently sensitive for detecting genetic disorders caused by inversions, balanced insertions, reciprocal translocations, polyploidy, low-level mosaicism $(<20 \%-$ $25 \%$ ), rearrangements in repeat sequences, point 
mutations, or duplications/deletions that are undetectable at the test's resolution level. The results of microarray testing are often complex and require confirmation and careful interpretation, often with the assistance of a medical geneticist.

The other genome-wide genetic tests reviewed, G-banded karyotyping and StFISH testing, have a lower sensitivity for abnormalities in similar populations of children with unexplained GDD/ID. There is consensus among clinical geneticists that microarrays should be considered first-line cytogenetic tests, preferred over StFISH testing and karyotyping, with karyotyping reserved for patients having signs of a specific chromosomal syndrome (e.g., Down syndrome), a family history of a chromosomal rearrangement, or a parent with a history of multiple miscarriages. ${ }^{\text {e109 }}$

Males with a history strongly suggestive of $\mathrm{X}$-linked inheritance may be considered for testing of one or more individual XLID genes or for screening of the entire X chromosome. Girls with severe impairment may be appropriate for testing for $M e C P 2$ mutations, regardless of whether the specific elinical features of Rett syndrome are present.

There may be greater suspicion for IEMs in children whose parents either are consanguineous or have had children with similar problems or unexplained death or fetal demise. Children with IEMs may have multiple organ system dysfunction, failure to thrive, dietary selectivity, unusual odors, hearing loss, or episodic symptoms, including seizures or encephalopathy. The importance of considering IEMs requires emphasis, because for some entities specific dietary or metabolic treatments may improve neurologic symptoms.

In addition to the clinical matters considered above it is important to remember that genetic testing is costly and may not be available to all families. Some of the critical matters related to the cost analysis of performing microarray testing are summarized in appendix $e^{-11}$.

\section{RECOMMENDATIONS FOR FUTURE RESEARCH}

Further prospective studies on the etiologic yields of various diagnostic tests need to be undertaken on large numbers of young children with GDD/ID and control subjects. Such studies should include newer molecular genetic and MRI technologies. With the resulting data, prospective testing of specific evaluation paradigms will be possible.

2. Features (i.e., markers) present on the history and physical examination at intake need to be identified that will improve specific evaluation strategies and enhance etiologic yield.
3. More information is needed about testing younger children with mild GDD who may have normal cognitive function. It would be helpful to know which children have a sufficient degree of delay to justify testing. Alternative strategies of conducting testing simultaneously or sequentially need to be critically assessed. Such information should help reduce unnecessary testing and provide cost-effective evaluations and more accurate diagnostic yields. Protocols for testing need to be compared to determine which are most appropriate in different clinical scenarios.

4. Research is sorely lacking on the medical, social, and financial benefits of having an accurate etiologic diagnosis. It may be that testing for relatively rare IEMs has a more substantial impact on families and society than testing for genetic syndromes, given how often the diagnosis directly influences patient treatment and outcome. The ability to rate diagnostic tests on the basis of factors other than diagnostic yield, such as the availability of effective treatment, would have a positive influence on clinical practice.

\section{AUTHOR CONTRIBUTIONS}

Dr. Michelson: drafting/revising the manuscript, analysis or interpretation of data, statistical analysis. Dr. Shevell: drafting/revising the manuscript, study supervision. Dr. Sherr: drafting/revising the manuscript, study concept or design, analysis or interpretation of data. Dr. Moeschler: drafting/revising the manuscript. Dr. Gropman: drafting/revising the manuscript, study concept or design, acquisition of data. Dr. Ashwal: drafting/revising the manuscript, study concept or design, analysis or interpretation of data, study supervision.

\section{DISCLOSURE}

Dr. Michelson reports no disclosures. Dr. Shevell was an author of a study cited in this evidence report for which Signature Genomics provided microarray testing "in kind." He has also given talks on microarray use for which Signature Genomics paid the travel expenses but did not pay honoraria. Dr. Sherr receives research support from Pfizer Inc, the NIH/ NINDS, the March of Dimes, the Aicardi Syndrome Foundation, Weston Havens Foundation, and Simons Foundation; holds stock/stock options in Sensorin, Plexxicon, Inc., Ingenuity Systems (by whom his wife is employed), and ChemoCentryx, Inc.; and has participated in medicolegal cases. Dr. Moeschler has received honoraria from the American Academy of Pediatrics and has received research support from US Health Resources and Services Administration and the Centers for Disease Control. Dr. Gropman has received funding for travel and speaker honoraria from BioMarin Pharmaceutical Inc.; has served as a consultant for BioMarin Pharmaceutical Inc., Bioreference Laboratories, and Genzyme Corporation; and receives research support from the NIH. Dr. Ashwal serves on the editorial board of Pediatric Neurology; receives royalties from publishing Pediatric Neurology: Principles and Practice (Elsevier, 2006); and receives research support from the NIH.

\section{DISCLAIMER}

This statement is provided as an educational service of the American Academy of Neurology and the Child Neurology Society. It is based on as assessment of current scientific and clinical information. It is not intended to include all possible proper methods of care for a particular neurological problem or all legitimate criteria for choosing to use a specific procedure. Neither is it intended to exclude any reasonable alternative methodologies. The AAN and the CNS recognize that specific patient care decisions 
are the prerogative of the patient and the physician caring for the patient, based on all of the circumstances involved. The clinical context section is made available in order to place the evidence into perspective with current practice habits and challenges. No formal practice recommendations should be inferred.

\section{CONFLICT OF INTEREST}

The American Academy of Neurology is committed to producing independent, critical and truthful clinical practice guidelines (CPGs) and evidence reports (ERs). Significant efforts are made to minimize the potential for conflicts of interest to influence the conclusions of this ER. To the extent possible, the AAN keeps separate those who have a financial stake in the success or failure of the products appraised in the ER and the developers of the systematic review. Conflict of interest forms were obtained from all authors and reviewed by an oversight committee prior to project initiation. AAN limits the participation of authors with substantial conflicts of interest. The AAN forbids commercial participation in, or funding of, systematic reviews. Drafts of the report have been reviewed by at least three AAN committees, a network of neurologists, Neurolog $y^{\circledR}$ peer reviewers, and representatives from related fields. The AAN Guideline Author Conflict of Interest Policy can be viewed at http://www.aan.com.

\section{REFERENCES}

1. Petersen MC, Kube DA, Palmer FB. Classification of developmental delays. Semin Pediatr Neurol 1998;5:2-14.

2. Yeargin-Allsopp M, Murphy CC, Cordero JF, et al. Reported biomedical causes and associated medical conditions for mental retardation among 10 year old children, metropolitan Atlanta, 1985 to 1987. Dev Med Child Neurol 1997;39:142-149.

3. Shevell MI, Ashwal S, Donley D. Practice parameter; evaluation of the child with global developmental delay. Neurology 2003;60:367-380.

4. Shinawi M, Cheung SW. The array CGH and its clinical applications. Drug Discoyery Today 2008;13:760-770.

5. Moeschler JB. Medical genetics diagnostic evaluation of the child with global developmental delay or intellectual disability. Gurr Opin Neurol 2008;21:117-122.

6. Aradhya S, Manning MA, Splendore A, Cherry AM. Whole-genome array-CGH identifies novel contiguous gene deletions and duplications associated with developmental delay, mental retardation, and dysmorphic features. AmJ Med Genet A 2007;143A:1431-1441.

7. Nowakowska B, Stankiewicz P, Obersztyn E. Application of metaphase HR-CGH and targeted chromosomal microarray analyses to genomic characterization of $116 \mathrm{pa}-$ tients with mental retardation and dysmorphic features. Am J Med Genet A 2008;146A:2361-2369

8. Schoumans J, Ruivenkamp C, Holmberg E, Kyllerman M, Anderlid BM, Nordenskjold M. Detection of chromosomal imbalances in children with idiopathic mental retardation by array based comparative genomic hybridisation (array-CGH). J Med Genet 2005;42:699-705.

9. Fan YS, Jayakar P, Zhu H. Detection of pathogenic gene copy number variations in patients with mental retardation by genomewide oligonucleotide array comparative genomic hybridization. Hum Mutat 2007;28:1124-1132.

10. Thuresson AC, Bondeson ML, Edeby C. Whole-genome array-CGH for detection of submicroscopic chromosomal imbalances in children with mental retardation. Cytogenet Genome Res 2007;118:1-7.

11. Bar-Shira A, Rosner G, Rosner S, Goldstein M, OrrUrtreger A. Array-based comparative genome hybridization in clinical genetics. Pediatr Res 2006;60:353-358.

12. Lybaek H, Meza-Zepeda LA, Kresse SH, Hoysaeter T, Steen VM, Houge G. Array-CGH fine mapping of minor and cryptic HR-CGH detected genomic imbalances in 80 out of 590 patients with abnormal development. Eur J Hum Genet 2008;16:1318-1328.

13. Rosenberg C, Knijnenburg J, Bakker E. Array-CGH detection of micro rearrangements in mentally retarded individuals: Clinical significance of imbalances present both in affected children and normal parents. J Med Genet 2006; 43:180-186.

14. Menten B, Maas N, Thienpont B, et al. Emerging patterns of cryptic chromosomal imbalance in patients with idiopathic mental retardation and multiple congenital anomalies: a new series of 140 patients and review of published reports. J Med Genet 2006;43:625-633.

15. Miyake N, Shimokawa O, Harada N, et al. BAC array CGH reveals genomic aberrations in idiopathic mental retardation. Am J Med Genet A 2006;140:205-211.

16. Tyson C, Harvard C, Locker R, et al. Submicroscopic deletions and duplications in individuals with intellectual disability detected by array-CGH. Am J Med Genet A 2005; 139:173-185.

17. Joly G, Lapierre JM, Ozilou C, et al. Comparative genomic hybridisation in mentally retarded patients with dysmorphic features and a normal karyotype. Clin Genet 2001;60:212-219.

18. Engels $\mathrm{H}$, Brockschmidt A, Hoischen A, et al. DNA microarray analysis identifies candidate regions and genes in unexplained mental retardation. Neurology 2007;68:743750.

19. Friedman JM, Baross A, Delaney AD, et al. Oligonucleotide microarray analysis of genomic imbalance in children with mental retardation. Am J Hum Genet 2006;79:500-513.

20. Harada N, Hatchwell E, Okamoto N, et al. Subtelomere specific microarray based comparative genomic hybridisation: a rapid detection system for cryptic rearrangements in idiopathic mental retardation. J Med Genet 2004;41:130-136.

21. Newman WG, Hamilton S, Ayres J, et al. Array comparative genomic hybridization for diagnosis of developmental delay: an exploratory cost-consequences analysis. Clin Genet 2007;71:254-259.

22. Vissers LELM, de Vries BBA, Osoegawa K. Array-based comparative genomic hybridization for the genomewide detection of submicroscopic chromosomal abnormalities. Am J Hum Genet 2003;73:1261-1270.

23. Shaw-Smith C, Redon R, Rickman L. Microarray based comparative genomic hybridisation (array-CGH) detects submicroscopic chromosomal deletions and duplications in patients with learning disability/mental retardation and dysmorphic features. J Med Genet 2004;41:241-248.

24. Shevell MI, Bejjani BA, Srour M, Rorem EA, Hall N, Shaffer LG. Array comparative genomic hybridization in global developmental delay. Am J Med Genet B 2008; 147B:1101-1108.

25. Krepischi-Santos AC, Vianna-Morgante AM, Jehee FS, et al. Whole-genome array-CGH screening in undiagnosed syndromic patients: old syndromes revisited and new alterations. Cytogenet Genome Res 2006;115:254-261.

26. Sharp AJ, Hansen S, Selzer RR, et al. Discovery of previously unidentified genomic disorders from the duplication architecture of the human genome. Nat Genet 2006;38: $1038-1042$.

27. Kriek M, Knijeneburg J, White SJ. Diagnosis of genetic abnormalities in developmentally delayed patients: A new strategy combining MLPA and array-CGH. Am J Med Genet A 2007;143A:610-614. 
28. de Vries BBA, Pfundt R, Leisink M. Diagnostic genome profiling in mental retardation. Am J Hum Genet 2005; 77:606-616.

29. Shaffer LG, Kashork CD, Saleki R. Targeted genomic microarray analysis for identification of chromosome abnormalities in 150 consecutive clinical cases. J Pediatr 2006; 149:98-102.

30. Shao L, Shaw CA, Lu XY. Identification of chromosome abnormalities in subtelomeric regions by microarray analysis: a study of 5,380 cases. Am J Med Genet A 2008;146A: 2242-2251.

31. Xiang B, Li A, Valentin D, Nowak NJ, Zhao H, Li P. Analytical and clinical validity of whole-genome oligonucleotide array comparative genomic hybridization for pediatric patients with mental retardation and developmental delay. Am J Med Genet A 2008;146A:1942-1954.

32. Pickering DL, Eudy JD, Olney AH, et al. Array-based comparative genomic hybridization analysis of 1176 consecutive clinical genetics investigations. Genet Med 2008; 10:262-266.

33. Shiue CN, Lin YH, Kuan LC, et al. Cytogenetic surveillance of mentally-retarded school children in southern Taiwan. J Formos Med Assoc 2004;103:218-224.

34. Battaglia A, Bianchini E, Carey JC. Diagnostic yield of the comprehensive assessment of developmental delay/mental retardation in an institute of child neuropsychiatry. Am J Med Genet 1999;82:60-66.

35. Volcke P, Dereymaeker AM, Fryns JP, van den Berghe $\mathrm{H}$. On the nosology of moderate mental retardation with special attention to X-linked mental retardation: a diagnostic genetic survey of 274 institutionalized moderately mentally retarded men. Genet Couns 1990;1:47-56.

36. Ahmed MN, DeLong GR, Qumsiyeh MB. Postnatal developmental delay and chromosomal abnormalities. Clin Pediatr 2000;39:233-235.

37. Cora T, Demirel S, Acar A. Chromosomal abnormalities in mentally retarded children in the Konya region: Turkey. Genet Couns 2000;11:53-55.

38. Graham SM, Selikowitz M. Chromosome testing in children with developmental delay in whom the aetiology is not evident clinically. J Paediatr Child Health 1993;29: 360-362.

39. Lamont MA, Dennis NR, Seabright M. Chromosome abnormalities in pupils attending ESN/M schools. Arch Dis Child 1986;61:223-226.

Shevell MI, Majnemer A, Rosenbaum P, Abrahamowicz M. Etiologic yield of subspecialists' evaluation of young children with global developmental delay. J Pediatr 2000; 136:593-598.

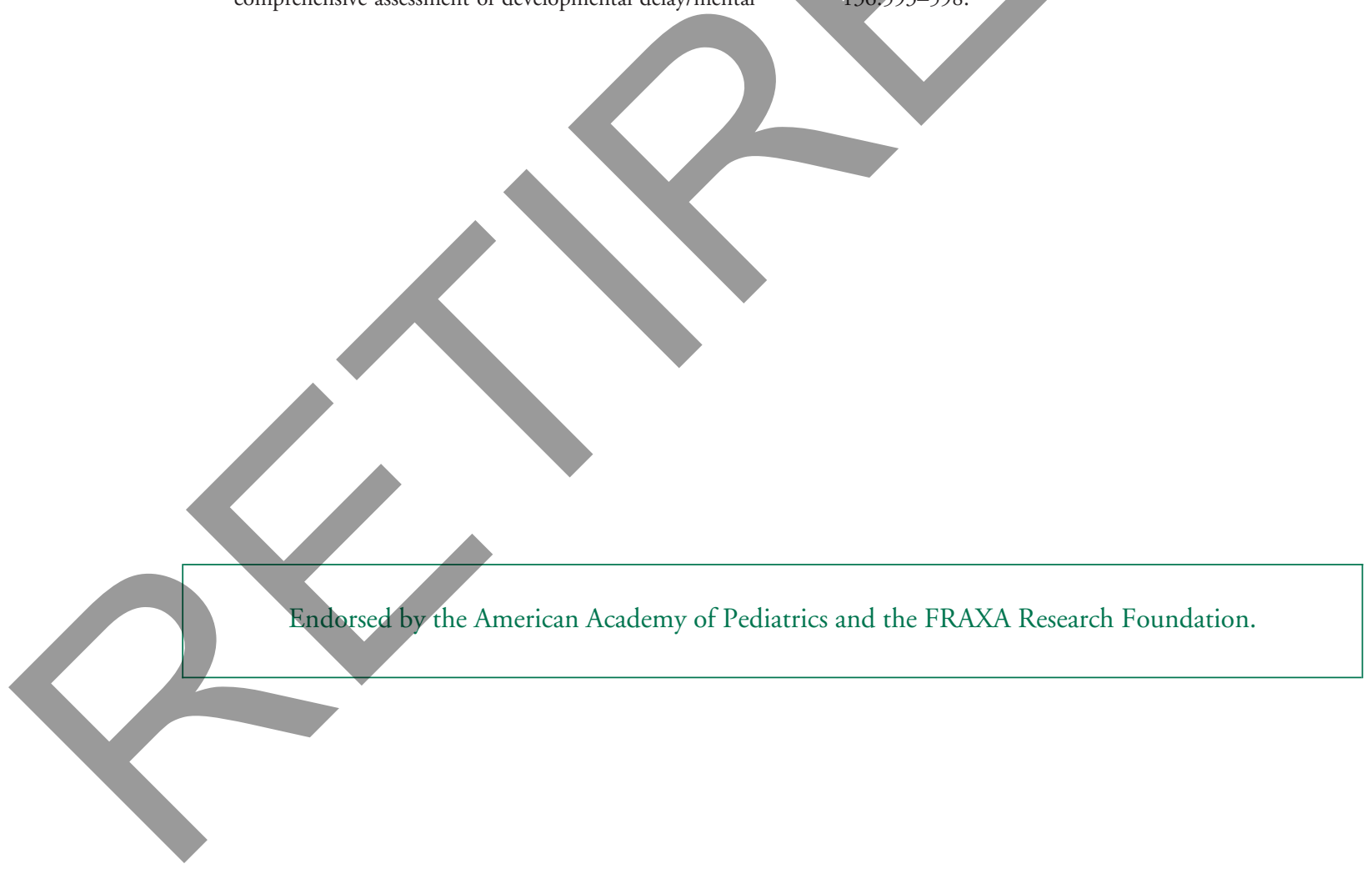




\section{Neurology}

\section{Evidence Report: Genetic and metabolic testing on children with global developmental delay [RETIRED]: Report of the Quality Standards Subcommittee of the American Academy of Neurology and the Practice Committee of the Child Neurology Society D.J. Michelson, M.I. Shevell, E.H. Sherr, et al.}

Neurology 2011;77;1629-1635 Published Online before print September 28, 2011

DOI 10.1212/WNL.0b013e3182345896

This information is current as of September 28, 2011

\section{Updated Information \& Services}

Supplementary Material

Citations

Subspecialty Collections

Permissions \& Licensing

Reprints including high resolution figures, can be found at: http://n.neurology.org/content/77/17/1629.full

Supplementary material can be found at: http://n.neurology.org/content/suppl/2011/09/28/WNL.0b013e3182345 896.DC2

http://n.neurology.org/content/suppl/2011/09/28/WNL.0b013e3182345 896.DC1

This article has been cited by 11 HighWire-hosted articles: http://n.neurology.org/content/77/17/1629.full\#\#otherarticles

This article, along with others on similar topics, appears in the following collection(s):

All Genetics

http://n.neurology.org/cgi/collection/all_genetics

\section{All Pediatric}

http://n.neurology.org/cgi/collection/all_pediatric

Developmental disorders

http://n.neurology.org/cgi/collection/developmental_disorders

Mental retardation

http://n.neurology.org/cgi/collection/mental_retardation

Information about reproducing this article in parts (figures,tables) or in its entirety can be found online at:

http://www.neurology.org/about/about_the_journal\#permissions

Information about ordering reprints can be found online:

http://n.neurology.org/subscribers/advertise

Neurology ${ }^{\circledR}$ is the official journal of the American Academy of Neurology. Published continuously since 1951, it is now a weekly with 48 issues per year. Copyright Copyright $@ 2011$ by AAN Enterprises, Inc.. All rights reserved. Print ISSN: 0028-3878. Online ISSN: 1526-632X.

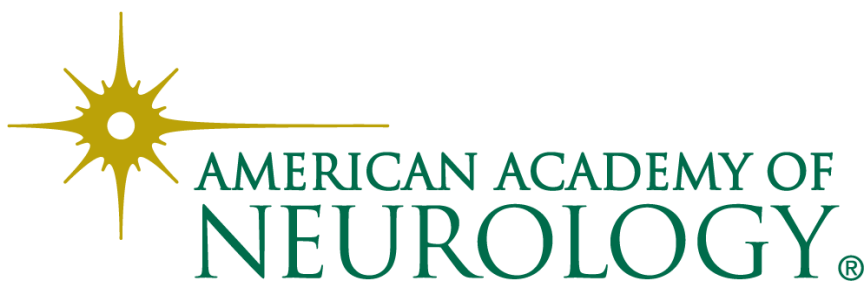

